\title{
Ethnobotanical Study of Medicinal Plants in Sub region Logo Anseba, Region Gash Barka, Eritrea
}

\author{
Biniam Yemane, Yohannes Berhane and Dr Kunduru Surender Reddy \\ Department of Biology, Eritrea Institute of Technology, P. O. Box 126 76, Mai Nefhi, Eritrea \\ Email: ksreddy.eit@gmail.com \\ Tel no: 002917581072 \\ Email: biniamgigi@yahoo.com \\ Tel no: 002917247144
}

\begin{abstract}
An ethnobotanical study was conducted to investigate the use of medicinal plants Sub region Logo Anseba, Region Gash Barka, of Eritrea. Information was gathered from 100 informants and 25 are traditional healers, using semi-structured questionnaire and the informants were selected systematically. In total 115 species belonging to 90 genera and 49 families were recorded. Taxa commonly used belong to 4 families such as Fabaceae (11.7 \%), Lamiaceae (8.3\%), Solanaceae (7.5\%) and Asteraceae (6.7\%) in number of species. Shrubs formed a major component (43.6\%) while herbs, trees, climbers and trailing herbs constitute $36.1 \%$, $17.3 \%, 2.3 \%$ and $1.5 \%$ respectively. The most frequently used plant parts for the preparations of remedy were leaves $(61 \%)$, roots (21\%), fruits (11\%) stem (5\%), and latex (2\%). These medicinal plant parts were processed in various forms and the major ones include crushing (30.1\%) powdering (18.1\%), boiling (17.3\%), chewing taking the solution (12\%), unprocessed (8.3\%), latex collection (4.5\%), smoking/inhaling (3.8\%) and chewing (3\%). The main threats to medicinal plants in the study area were fire wood, grazing, agricultural expansion, construction and drought. Based on the findings given above the following recommendations are forwarded: further scientific investigations are needed for the isolation of active principles and pharmacological evaluation of different medicinal plant species reported in this study, medicinal plant management and conservation must be integrated in other sectors such as in health to foster better use of plant materials and education to build up awareness for protection and government must also support local medicines and provide incentives to farmers for cultivation of medicinal plants to ensure conservation issues.
\end{abstract}

Keywords: ethnobotany, conservation, healthcare, indigenous knowledge, traditional medicinal plant

\section{Introduction}

Plants provide people with food, medicines, as well as materials for construction and the manufacture of crafts and tools and many other products like fuel, paints and poisons. According to World Health Organization report, more than $80 \%$ of the people in Africa depend on traditional medicine for their health care needs (WHO, 2003). And globally about $64 \%$ of the total world population remains dependent on traditional medicine for their healthcare needs. (Prakash et al 2015)

In recent years, various plants are used as a subject to medical experiment. In particular, herbal plants are recognized as one of the intriguing subjects from which the extracts can be used in health care setting for future purpose. Moreover, because of global warming, deforestation, grazing, agricultural expansion and drought in sub Saharan countries including Eritrea; many valuable medicinal plants are rare and are on the verge of extinction (Cotton, 1996).

Eritrean society has a long history of practicing traditional/ herbal medicine that also has links to cultural values and beliefs. In this context, traditional medicine is concerned with types of medical treatment and practices that are based on customary knowledge. In some rural part of Eritrea large number of population are still reliant on traditional medicine. Traditional medical practices are quite varied based on cultural diversity. While a majority of traditional healers deal with human diseases, some also specialize in the treatment of animal diseases, disease prevention, and the promotion of spiritual and physical well-being of community members (Senai, 2010).

Ethnobotanical knowledge of medicinal plants in the high lands of Eritrea is transferred from the older people to younger generations at household level and this knowledge is not ongoing in written form, so that their losses or distortion at every transfer is inevitable (Shushan, 2002).

According to Tecleab et al., (2006), Ethnobotanical survey was conducted in region Maekel and region Semenawi Keih-Bahri. The survey includes Asmara, Belza, Shegrini, Betgirgish, Areberubu, Adi guadad, Maihinzi, and Gihndae. These areas are inhibited byTigrna, Tigre, and Saho ethnic groups. Information was obtained using digital record, free-listing, semi-structured and open-ended interviews with traditional healers, community elders, and mothers. Nine medicinal plants that used to treat diseases associated with bacteria were identified and the study justifies the traditional use of the plants in Eritrean traditional medicine. 
In spite of the vast role and important ethnobotanical contributions of medicinal plants in the primary health care, limited works have so far been done in the country (Senai, 2010; Thomas et al., 2007; Tecleab et al., 2006 and Shushan, 2002). This study has therefore been initiated to document the plants used in the traditional medical practices of the people of sub region Logo-Anseba together with the associated ethnobotanical and ethnomedicinal knowledge and practices.

The objectives of this paper are to identify and record traditionally important medicinal plants for the treatment of human being, to document the indigenous knowledge of the people on the use of medicinal plants in the study area, to identify plant parts used for medicinal purposes together with their method of preparation and route of administration, and to contribute to the conservation of medicinally important plants that are used in the study area.

\subsection{Description of the Study Area}

\section{Materials and Methods}

Sub region Logo Anseba is a sub region in the western part of Gash Barka of Eritrea. The sub region is bordered by the Anseba, Maekel and Debub sub regions (Figure 1). It sits at an altitude between 1600-2400 meters above sea level, with a semi-arid climate. The total population of Logo Anseba is 33,446; it is composed of 16 local administrative sites, and 22 villages. Tigrigna and Arabic are the main spoken languages in the sub region. Most of the inhabitants of Logo Anseba live by farming, cultivating wheat, sorghum, finger millet and pulses. During the dry season from November to March, the inhabitants perform other work such as trade and construction. Logo Anseba is the origin for one of the main rivers, the Barka River, which flows all the way into Sudan (CSOGB, 2010).

\subsection{Survey and Selection of Informants}

A survey was conducted from January- May 2016 in the study site in order to obtain the data about medicinal plants, on the general physiognomy of vegetation and to identify sampling site. During the survey, 22 representative sites (villages) distributed in the 16 local administrations were selected.

A total of 100 informants including $25 \mathrm{key}$ informants for the local knowledge on traditional medical plants were selected. The selection of key informants was done according to Martin, (1995).

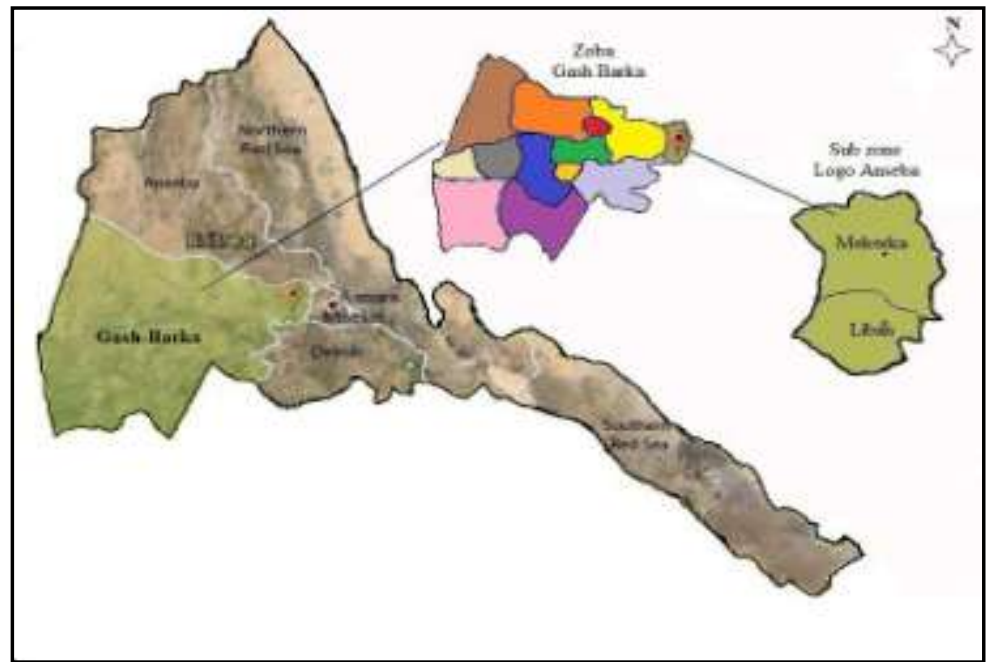

Figure 1: Map of the Study Area-Logo Anseba (Source: - Google Earth)

\subsection{Ethnobotanical Data Collection}

Ethnobotanical data were obtained from both primary and secondary sources. The primary sources were interview and group discussion in the field of the study area, whereas the secondary data sources were from various and relevant literature. The information on the local names, ailments and diseases treated, parts of plants used, methods of preparation, methods of administration, doses, duration of the treatment were obtained from local people through individual interviews.

The selection of respondents from each village was based on the following criteria: that they have been living in the sub region for many years, use plants as the main medicine or identified as medicinal plant extractors. The information gathered was checked with other areas, neighboring villages, to verify the accuracy. The key informants were asked how, when, in this cases, both the harmful and useful effects of the used plants in detailed questions. 
Ethnobotanical techniques were employed to collect data on knowledge and management of medicinal plants used by the local people in the study area. The methods used for ethnobotanical data collection was semistructured interview following Cotton, (1996) and Martin, (1995), field observation and after all this detail group discussion with key informants.

\subsection{Voucher Specimen Collection}

Specimens of medicinally useful plants were collected from various habitats at the spot during guided field work, numbered, pressed, and dried for identification. Identification of specimens was carried out both in the field and in the herbarium in the Department of Biology at Eritrean Institute of Technology. The nomenclature determination was carried out using various volumes of Flora of Ethiopia and Eritrea. The voucher specimens were kept in the herbarium in the Department of Biology at Eritrea Institute of Technology.

\subsection{Vegetation Description}

Two approaches were used in describing the vegetation of the study area. In the first approach, information was gathered from informants following the emic categorization technique that is categorization by indigenous people based on their own indigenous knowledge. The second one was described and classified through repeated curious visual observation following the etic classification technique of Ethnobotany as described by Martin, (1995). In the latter case, morphological characteristics or general appearance of vegetation such as growth and life forms of the dominant or co-dominant plants were focused on.

Based on visual observation, the vegetation of the study area can be classified as:

$>$ Acacia etbaica Community

$>$ Dodonea angustifolia Community

$>$ Becium grandiflorum Community

$>$ Euphorbia abyssinica Community

$>$ Euclea racemosa Community

$>$ Ficus vasta Community

\subsection{Ethnobotanical Data Analysis}

The collected ethnobotanical data were analyzed following survey and analytical tools for Ethnobotanical methods, which is recommended by WHO, (2003). Appropriate software, IBM SPSS statistical version 20, was used for data analysis. Informant consensus factor, preference ranking, direct matrix ranking and paired comparison were computed to assess the degree of effectiveness of certain medicinal plants to treat human beings.

\section{Results and Discussion \\ 3.1 Acquisition, Threat, Transfer and Basic Information of the Traditional Medicinal Plants (TMP) Knowledge}

The age of the informants lie between 45 and 97 years. The highest number is in the age group between 56 and 97. This shows that the elders were more knowledgeable because of the many years accumulated experience. During this study, it has been found that the main sources of Traditional Medicinal Knowledge (TMK) are parents - 54\% followed by observation - $32 \%$, trial and error - $6 \%$ and other acquaintances and knowledgeable persons - $8 \%$. Medicinal plant knowledge, use and transfer of knowledge to the young generation can be affected by religious beliefs, modernization, acculturation, and environmental change (Cunningham, 1996).

Ethnomedicinal knowledge diminishes with death of elderly knowledgeable members of the community since only a few young people are willing to acquire the knowledge. Gathering and processing of many medicinal plants were restricted to traditional medicinal practitioners and their trainees. At family level, it is restricted to the elders (men and women), followed by the elder son or daughter or their trustworthy person when the mother or the father is getting old or about to die (Debela et al., 2004).

In a similar fashion, the respondents in the study site also reported that the transmission of traditional knowledge is disrupted because of modernization, rapid changes in people's life style and death of elder people. The death of elderly custodians of certain traditional knowledge will mean loss of certain practices, unless they are passed on to younger generations, since folk knowledge among the sub region people like many traditional tribes, is orally transmitted.

It is observed that most respondents transfer their knowledge to their family. This means that most of the traditional knowledge of medicinal plants is passed along the family line. First-born children in the family are the main holders of responsibility in keeping the information and they are the successors of their parents as well. Few others share to trustworthy and loved neighbors and other blood related persons. Exchange and knowledge sharing are also common among intimate key informants. 
A major problem observed during the study was that few of the highly traditional skilled and knowledgeable persons were unwilling to tell information. This is because, first, it is a means of income generation and their livelihood depends on the income they get out of it. Second, they believe that the medicinal plant is less effective in treating a certain ailment if everybody knows it. On the other hand, most of the time knowledgeable persons were locally said to be 'Debtera'or 'Tenqualay'. They were also condemned as 'Belaeiqotseli (leaf eaters). Because of the above mentioned difficulties, the traditional medicine practitioners are forced to keep their knowledge and practices in secret.

Nevertheless, farmers, students and other educated inhabitants are free to share information more. In comparison with males, females are sensitive and afraid of the taboo words forwarded by the local people. That is why the number of female informants in the study area was less than that of males.

\subsection{Medicinal Plants used to Treat Human Ailments}

A total of 115 medicinal plant species, belonging to 90 genera 49 families were recorded (see appendix). The most widely used species belongs to the families Fabaceae, Lamiaceae, Solanaceae and Asteraceae. For details refer (Table 1 and appendix 1).

Table1: Medicinal Plants and their Families that are Used to Treat Human Ailments

\begin{tabular}{|l|l|}
\hline Family's Name & Number of species \\
\hline Fabaceae & 14 \\
\hline Lamiaceae & 10 \\
\hline Solanaceae & 9 \\
\hline Asteraceae & 8 \\
\hline Euphorbiaceae & 6 \\
\hline Boraginaceae & 3 \\
\hline Myrtaceae & 4 \\
\hline Rhamnaceae & 4 \\
\hline Acanthaceae & 4 \\
\hline Anacardiaceae & 4 \\
\hline Cucurbitaceae & 3 \\
\hline Capparidaceae & 3 \\
\hline Apiaceae & 3 \\
\hline Poaceae & 3 \\
\hline Rutaceae & 3 \\
\hline Vitaceae & 3 \\
\hline Malvaceae & 3 \\
\hline Brasicaceae & 3 \\
\hline Other 31 Families & 2 or 1 \\
\hline
\end{tabular}

The preference ranking indicated that, the most preferred medicinal plants to treat Malaria among 15selected plant species was Terminalia brownii and was followed by Senna alexandrina, Euphorbia camaldulensis, Aloe elegance, Phytolacca dodecandra, and Cordia africana. The most preferred plants to treat tonsillitis are ranked below and are given by seven key respondents (Table 2).

Table 2: Ranking of Medicinal Plant used to Treat Tonsillitis based on Seven Respondents $\left(\mathrm{R}_{1}-\mathrm{R}_{7}\right)$

\begin{tabular}{|l|l|l|l|l|l|l|l|l|l|}
\hline Medicinal Plants & $\mathrm{R}_{1}$ & $\mathrm{R}_{2}$ & $\mathrm{R}_{3}$ & $\mathrm{R}_{4}$ & $\mathrm{R}_{5}$ & $\mathrm{R}_{6}$ & $\mathrm{R}_{7}$ & Total & Rank \\
\hline Terminalia brownii & 4 & 4 & 4 & 5 & 5 & 5 & 4 & 31 & 1 \\
\hline Senna alexandrina & 4 & 3 & 4 & 4 & 4 & 4 & 5 & 28 & 2 \\
\hline Euphorbia camaldulensis & 4 & 4 & 3 & 3 & 3 & 3 & 4 & 24 & 3 \\
\hline Aloe elegance & 4 & 3 & 3 & 3 & 3 & 3 & 4 & 23 & 4 \\
\hline Phytolacca dodecandra & 3 & 3 & 3 & 4 & 3 & 3 & 3 & 22 & 5 \\
\hline Cordia africana & 3 & 3 & 3 & 3 & 3 & 3 & 3 & 21 & 6 \\
\hline
\end{tabular}

Direct matrix of randomly selected 10 medicinal plants with different uses other than medicinal value on a given use criteria revealed that medicinal plants are broadly collected for different purposes (Table-3). 
Table 3: Direct matrix ranking of medicinal plants with different uses in the study areas.

\begin{tabular}{|c|c|c|c|c|c|c|c|c|c|c|c|c|}
\hline Main uses & 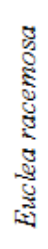 & 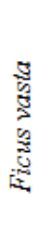 & 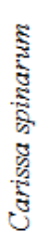 & 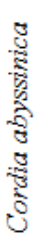 & 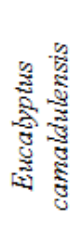 & 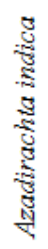 & 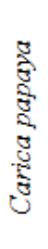 & 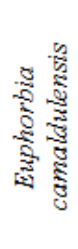 & 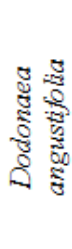 & 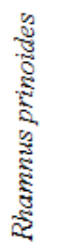 & $\begin{array}{l}\text { च्ञ } \\
0\end{array}$ & 䮈 \\
\hline Construction & 3 & 5 & 3 & 5 & 5 & 5 & 3 & 5 & 5 & 3 & 42 & 2 \\
\hline Edible fruit & 0 & 3 & 0 & 4 & 0 & 0 & 5 & 0 & 0 & 2 & 14 & 6 \\
\hline Forage & 2 & 0 & 1 & 3 & 0 & 0 & 3 & 1 & 1 & 0 & 11 & 7 \\
\hline Fuel wood & 4 & 5 & 4 & 4 & 5 & 4 & 4 & 5 & 5 & 4 & 44 & 1 \\
\hline Furniture & 3 & 4 & 3 & 5 & 5 & 5 & 2 & 2 & 4 & 1 & 34 & 5 \\
\hline Medicine & 4 & 5 & 4 & 3 & 3 & 3 & 3 & 4 & 4 & 4 & 37 & 4 \\
\hline Soil conservation & 4 & 5 & 4 & 3 & 3 & 5 & 3 & 5 & 5 & 3 & 40 & 3 \\
\hline Total & 20 & 27 & 19 & 23 & 21 & 22 & 23 & 22 & 24 & 17 & & \\
\hline Rank & 8 & 1 & 9 & 3 & 7 & 5 & 4 & 5 & 2 & 10 & & \\
\hline
\end{tabular}

Paired comparison of 8 selected medicinal plants out of 20 plant species that were used to treat fungal diseases based on informant consensus showed that Ziziphus spina-christi, Rhamnus prinoides, Acacia etbaica, Dodonaea angustifolia, Euclea racemosa, Leucas martinicense, Ficus vasta and Terminalia brownii stood $1^{\text {st }}$ $8^{\text {th, }}$ respectively. The most preferred plants to treat fungal diseases are ranked below and are given by eight key respondents (Table-4)

Table 4: Paired comparisons of medicinal plants used to treat fungal diseases based on eight respondents $\left(\mathrm{R}_{1}-\mathrm{R}_{8}\right)$

\begin{tabular}{|l|l|l|l|l|l|l|l|l|l|l|}
\hline Name of Medicinal plants & $\mathrm{R}_{1}$ & $\mathrm{R}_{2}$ & $\mathrm{R}_{3}$ & $\mathrm{R}_{4}$ & $\mathrm{R}_{5}$ & $\mathrm{R}_{6}$ & $\mathrm{R}_{7}$ & $\mathrm{R}_{8}$ & Total & Rank \\
\hline Ficus vasta & 1 & 2 & 2 & 2 & 1 & 2 & 2 & 2 & 14 & 7 \\
\hline Acacia etbaica & 4 & 3 & 2 & 4 & 3 & 3 & 3 & 1 & 23 & 3 \\
\hline Leucas martinicense & 2 & 2 & 2 & 2 & 3 & 2 & 3 & 2 & 18 & 6 \\
\hline Ziziphus spina-christi & 4 & 3 & 3 & 4 & 3 & 3 & 3 & 4 & 27 & 1 \\
\hline Dodonaea angustifolia & 3 & 2 & 3 & 3 & 3 & 2 & 3 & 2 & 21 & 4 \\
\hline Euclea racemosa & 2 & 3 & 2 & 3 & 2 & 3 & 1 & 3 & 19 & 5 \\
\hline Terminalia brownie & 2 & 2 & 2 & 1 & 2 & 2 & 1 & 1 & 13 & 8 \\
\hline Rhamnus prinoides & 4 & 3 & 4 & 3 & 3 & 3 & 3 & 2 & 25 & 2 \\
\hline
\end{tabular}

As shown in Table-5, the highest informants consensus factor (ICF) 0.67 value was associated with gastrointestinal problems such as stomachache, gastritis, diarrhea, dysentery, constipation, abdominal helminthes, vomiting, ascariasis and tapeworm followed by ICF 0.66 dermatological/skin problems such as wounds, cuts, burns, scabies, dandruff, ringworm, eczema and leshmaniasis then with diseases associated with organ diseases such as teeth, liver, heart, ear and eye etc 0.48 , diseases related to respiratory problem 0.45 then with "Weqeiie (sun strike), Gonfii and Evil eye 0.48, diseases related to Malaria, hepatitis, hepatomegaly and megalomegaly 0.38 and the category of the lowest ICF 0.27 value was associated "Weqeii"e (sun strike), Gonfii and Evil eyes.

This shows that medicinal plants, which have higher informants consensus factor (ICF) values, are assumed effective in treating a certain ailment. Informants consensus factor (ICF) was calculated as number of use citations in each category (Nuc) minus the number of species used (Ns) divided by the numbers of use citations in each category minus one (Martin, 1995).

$$
\mathrm{ICF}=\frac{N u c-N s}{N u c-1}
$$

Similarly Nugusse, (2010) reported high proportion of remedy for the treatment gastrointestinal problems $(0.74)$ dermatological/skin problems with ICF (0.66) followed by in Ethiopia. 
Table 5: ICF by category of diseases (Key: Ns-number of species, Nuc-Number of use citation)

\begin{tabular}{|l|l|l|l|}
\hline Diseases Related to & Ns & Nuc & ICF \\
\hline Gastrointestinal problems. & 30 & 90 & 0.67 \\
\hline Dermatological problems. & 27 & 78 & 0.66 \\
\hline Organs such as liver, heart, kidney ,teeth, ear, eye etc. & 16 & 30 & 0.48 \\
\hline Respiratory problems: cough, common cold, TB etc. & 12 & 20 & 0.45 \\
\hline Malaria, hepatitis, hepatomegaly and megalomegaly. & 22 & 40 & 0.38 \\
\hline Sun-strike, "weqeii", "gonfii", etc. & 9 & 12 & 0.27 \\
\hline
\end{tabular}

\subsection{Sources and Habits of the Medicinal Plants}

Singhal, (2005) estimated that 90 per cent of plant material for a medicinal purpose is harvested from wild sources and includes a wide range of non-timber forest products (NTFPs) in the form of roots, seeds, skin, bark, flowers, fruits and leaves.

Similarly in the study area, most medicinal plants $(62 \%)$ are harvested from natural habitat in different natural communities, $(20 \%)$ harvested from home garden, $(8 \%)$ both in natural and home garden and $(10 \%)$ of the medicinal plants are available in markets of the study area.

The current findings show that the most widely used medicinal plants in the study area are shrubs followed by herbs. Results of the present findings agree with similar works done in Ethiopia (Debelaet al., 2004; Bayafers, 2000; Mirutse and Gobena, 2003; Ermias et al., 2008 and Fisseha et al., 2009).

\subsection{Plant Parts used and Modes of Preparation}

The findings show that $(71 \%)$ of the medicinal plants cited were used in fresh form in remedy preparations, $(22 \%)$ from dried parts and very small $(7 \%)$ were prepared from dried or fresh parts. Similar results were reported in the finding of Endalew, (2007).

Analysis of the data revealed that, leaves $(60 \%)$ and roots $(24 \%)$ were the most widely used plant parts in the preparation of remedies followed by others such as stem, bulb/tuber, latex, seed, stem/root barks, and fruits. Previous reports in Ethiopia have also shown that leaves were the most commonly used parts followed by roots to treat various health problems (Bayafers, 2000; Mirutse and Gobena, 2003).

During the preparation of traditional medicine from plants, the methods of preparations used by traditional healers were crushing, squeezing, powdering, and mixing with solvents and additives in liquid preparations. Most of the preparations of traditional medicinal plants involved the use of water as solvents. Butter and honey are also used in paste preparations. In certain cases, excretes of animal, were included in such preparations.

Additives like sugar, honey, tea, and coffee were used in most of the remedy preparations to make them tasty when taking the medicine. This is to reduce the bitterness of the medicine so that the patients take it easily.

The measurements used to determine the dosages are not standardized and depend on the age, physical appearance of the patient, degree of the illness, diagnosis and experience of individual healers or knowledgeable person. For instance children are given less than adults, such as, one fourth of a coffee cup whereas; an adult is given up to one glass depending on the type of illness and treatment. Similar results were reported in the finding of Dawit, (2001).

The amounts of remedy and prescription rates were generally dependent on the degree and duration of the ailment. Therefore, this study revealed that while there may be scope for improvement the methods, traditional treatments are not entirely devoid of all measurement and standards. For example, almost all informants demonstrated awareness of the toxicity of some plants and specific plant parts when administered in large doses. In some cases, the healers will give antidotes such as milk, coffee and 'sewa' (local alcohol) if the doses are beyond the patients' capacity.

The informants in the study area reported that some Medicinal Plants including, Ricinus communis, Datura stromonium, Prunus persica, Phytolacca dodecandra, Verbasicum siniaticum, Euphorbia abyssinica, and Croton macrostychus are poisonous to man if not handled with proper care. Similar result was reported in the finding of Nugusse, (2010).

Though these medicinal plants do have side effects, they are effective in treating different ailments. These emphasize how much the local people are aware of the use and side effects of MPs. Beside the medicinal properties of many plants have been scientifically proven in recent years. For example, Ricinus communis for the treatment of infection, Verbasicum siniaticum for the treatment of tapeworm, and Phytolacca dodecandra as a molluscicide in the control of schistosomiasis are plants from East Africa which have been proven as effective and safe (Russo, 2000).

The medicinal plant preparations were applied through different routes of administration. The common administration routes are oral $60(46.2 \%)$ followed by dermal $34(28.4 \%)$. Other routes of applications are nasal, ear, anal, nasal and oral, dermal, genital and anal. Similar results were observed by Dawit and Ahadu, 
(1993) who reported that the leading route of application used in northern Ethiopia is oral which accounted for $42 \%$. Those taken through the nose are either smoked or boiled in water and the patient inhales the smoke or the steam often being covered with cloth.

\subsection{The Top ten Medicinal Plants in the Study Area}

Medicinal plants that had high informants' consensus of $50 \%$ and above (10 species) are described below in (Table -6).

Table 6: Ten Most Widely Used Medicinal Plants in the Study Area

\begin{tabular}{|l|l|l|l|l|}
\hline Scientific name & Local name & No. of citation (frequency) & Informants consensus & Rank \\
\hline Schinus molle & Ee're & 88 & 88 & 1 \\
\hline Ficus vasta & Daero & 86 & 86 & 2 \\
\hline Meriandra dianthera & Nehba & 78 & 78 & 3 \\
\hline Aloe elegance \& Aloe camperi & Eree & 75 & 75 & 4 \\
\hline Ruta chalepensis & Chena-adam & 73 & 73 & \\
\hline Cordia Africana & Awhhi & 71 & 71 & \\
\hline Trigonella foenum- graecum & Abaake & 67 & 67 & 6 \\
\hline Eucalyptus camaldulensis & Qeieh-kelamitos & 64 & 64 & 7 \\
\hline Terminalia brownii & Weiba & 59 & 59 & 8 \\
\hline Senna alexandrina & Senno & 55 & 55 & 9 \\
\hline
\end{tabular}

\section{Schinus molle (Anacardiaceae)}

Medicinal uses: This plant is used to treat diarrhea, cold, coughing, sun stroke and abdominal pain. In other African countries it is also used to treat leshmaniasis (Amare, 1976)

Route of application: In the treatment of diarrhea the leaf is crushed, mixes with water and decanted in to a cup to be taken in the morning for 7 days. But in case of cold, cough and sun strike the leaf is crushed and mixed with water and applied on the skin.

\section{Ficus vasta (Moraceae)}

Medicinal uses: It is used to treat internal swell of abdomen and Snake bite. Similar result is also found in northern Ethiopia (Meaza. et al, 2015)

Route of application: In the treatment of internal swell of abdomen crushing the root, add small amount of water and drink a bottle cup in the morning for 7days.But in case of snake bite a ripened fruit fluid is mixed with butter and creamed over the body.

\section{Meriandra dianthera (Lamiaceae)}

Medicinal uses: It is used to treat hypertension and diabetes. Similar result is also found in northern Ethiopia (Bayafers, 2000).

Route of application: The Leaf is dried, crushed, boiled and decanted in to a cup to be taken in the morning until it reduced down

\section{Aloe camperi and Aloe elegance (Aloaceae)}

Medicinal Uses: The Latex of this plant species is used in traditional medicine as anti-fungal and antibiotics (WHO, 2003). The latex is also used to treat impotency (Dawit, 2001) its medicinal application in the study site includes for the treatment of malaria, hepatomegaly, splenomegaly, diabetics, abdominal pain, and as an antibiotic.

Route of application: The latex is taken as a droplet (example adult's get 3-droplet per day) through the mouth every morning until they get cured.

\section{Ruta chalepensis(Rutaceae)}

Medicinal uses: It is used to treat coughing, cold, abdominal pain and evil eyes. The root is used against stomach-ache, cough and influenza (Endalew, 2007) and it is also used to treat stomach-ache in Ethiopia (Nugusse, 2010).

Route of application: In case of coughing and cold the leaf or stem is crushed, mix with water and boiled then inhale the water vapor for $10 \mathrm{~min}$, for abdominal pain leaf or stem is crushed, mixed with water and decanted to be taken 3 tea spoon/ day for 7 days. And for evil eyes the leaf is crush and mixed with water and the patient smells it for about 7-10 minutes. 


\section{Cordia africana(Boraginaceae)}

Medicinal uses: It is used to treat jaundice, abdominal pains, and malaria. The use of the plant to treat jaundice and malaria has been also recorded in Ethiopia (Nugusse, 2010).

Route of application: For jaundice, abdominal pain and malaria the stembark is powdered, mixed with water and decanted to be taken orally 2 beakers per day for a week.

\section{Trigonella foenum-graecum(Fabaceae)}

Medicinal uses: It is used to treat hypertension, diabetes, abdominal pain, asthma and "spider disease" in case of spider disease people believes that the spider causes the skin trouble by depositing its urine or other forms of excretion on the skin while they are sleeping. Similarly this plant species is used in traditional medicines to treat other various diseases such as diabetes, cholesterol, anemia, itching, rheumatism, gastritis and enlarging of the female breast in Eritrea (Esknder, 2001).

Route of application: for hypertension, diabetes and abdominal pain the seed is crushed, mixed with water, boiled homogenized to be taken orally a beaker 3 times a day for 10 days. In case of asthma mixed with water and honey and given orally a glass 1 times a day for 14 days.

\section{Eucalyptus camaldulensis (Myrtaceae)}

Medicinal uses: This plant species is used to treat various diseases such as rheumatism, cough and is also used as an antibiotic and insecticide. The use of the plant to treat TB, bronchial infection, malaria and diabetes has been also pointed out in Eritrea by Esknder, 2001).

Route of application: In the treatment of Rheumatism and cough, the leaf is boiled in water and inhaled for 10 minutes. As an Antibiotic the leaf is crushed, mixed with water and apply in the injured part for 5 days. As an insecticide the leaf is crushed and burnt in fire for 5 minute, to release smoke.

\section{Terminalia brownii (Combreataceae)}

Medicinal uses: It is used to treat hepatitis, malaria, dandruff, and also conjunctivitis and other eye ailments. The roots are used against toothache (Singhal, 2005). Elsewhere in Africa, leaves are used against coughing (Iwu, 1993).

Route of application: In the treatment of Hepatitis and malaria the Stem bark is crushed and boiled in water then decanted into a cup to be taken in the morning. In case of dandruff the leaf is crushed and mixed with water and applied on the hair for three hours. For conjunctivitis the leaf or bark is crushed and boiled then taken as a droplet during the night for seven days.

\section{Senna singueana (Fabaceae)}

Medicinal uses: This plant species is used in traditional medicine to treat vomiting, loss of appetite, retain birth and hepatitis.

Route of application: In the treatment of vomiting, loss of appetite and hepatitis the stem bark is crushed, mixed with water, boiled and decanted to be taken orally a cup of glass for 5 days. In case of birth retention the stem bark is crushed, mixed with water and boiled to be inhaled.

\subsection{Threats, Management and Conservation of the Medicinal Plants}

Biodiversity loss in Africa is usually caused by expansion of investment activities, deforestation, overgrazing and expansion of agricultural activities, poverty and lack of appropriate policies that encourage conservation and management of biodiversity (Cotton, 1996). It is reported that several medicinal plants have already disappeared from their common habitat and some of them are at risk of extinction. People or traditional healers are forced to travel a long distance to obtain medicinal plants (Cotton, 1996).

As in other parts of Eritrea, plant resources are vital for the livelihood of the sub sub region Logoanseba people. However, the resources are eroded from time to time because of the increment of population. Associated with this, the demand of agriculture is high and therefore clearance of vegetation and/or forests are high.

As indicated in Table-7 the main threats on medicinal plants in the study area are fire wood $(22.7 \%)$, grazing $(21.3 \%)$, agricultural expansion (20\%), construction (18\%) and drought $(17.3 \%)$. In the study area, closures in shanshoqor area and other few villages are serving as conservation sites for many medicinal plants. These closures are protected by the local people in collaboration with the local administration. More over 
healers bring and plant the most threatened medicinal plants in their home gardens. The home garden is a strategic and ideal farming system for conservation, production and enhancement of medicinal plants and valuable indigenous knowledge (Asfaw, 2001).

Table-7 Ranking of threats on the medicinal plants (Key values 1-5: 1 is the least destructive threat and 5 are the most destructive one and R: represents the respondents)

\begin{tabular}{|l|l|l|l|l|l|l|l|l|l|l|l|}
\hline Major threats & $\mathbf{R}_{\mathbf{1}}$ & $\mathbf{R}_{\mathbf{2}}$ & $\mathbf{R}_{\mathbf{3}}$ & $\mathbf{R}_{\mathbf{4}}$ & $\mathbf{R}_{\mathbf{5}}$ & $\mathbf{R}_{\mathbf{6}}$ & $\mathbf{R}_{\mathbf{7}}$ & $\mathbf{R}_{\mathbf{8}}$ & Total & $\mathbf{\%}$ & Rank \\
\hline Agri-expansion & 4 & 5 & 4 & 3 & 3 & 2 & 4 & 5 & 30 & $20 \%$ & 3 \\
\hline Fire wood & 5 & 4 & 3 & 5 & 3 & 5 & 4 & 5 & 34 & $22.7 \%$ & 1 \\
\hline Construction & 4 & 3 & 2 & 4 & 4 & 5 & 3 & 3 & 28 & $18.7 \%$ & 4 \\
\hline Grazing & 3 & 4 & 5 & 3 & 5 & 4 & 5 & 3 & 32 & $21.3 \%$ & 2 \\
\hline Drought & 2 & 4 & 3 & 3 & 5 & 3 & 4 & 2 & 26 & $17.3 \%$ & 5 \\
\hline
\end{tabular}

Likewise, medicinal plants which have additional uses in the area, such as ornamental, fuel, forage, spice, food and soil conservation are planted on home gardens and farmlands. Plants such as, Allium sativum, Foeniculum vulgare, Lepidium sativum, Ruta chalepensis, Schinus molle, Vernonia amygdalina, Rhamnus prinoides sand few others are commonly planted. This implies that endangered species are the focus of ex-situ conservation. Therefore, it must be noted that sustainable medicinal plant management and conservation is not an option but imperative for rural health and community well-being especially primary health.

Among the recorded plants, five species are known to be sub regional endemics. Their conservation status is determined according to Vivero et al., (2005). Among these endemic plants, three species are of global conservation concern Aloe camperi and Aloe elegance, are vulnerable while Becium grandflorum is a near threatened species (Table 8).

Table 8: Sub Regional Endemic Species Recorded from the Local Study Area.

\begin{tabular}{|l|l|l|}
\hline Species & Distribution & Status \\
\hline Aloe camperi & Eritrea and N. Ethiopia & Vulnerable \\
\hline Aloe elegance & Eritrea and Ethiopia & Vulnerable \\
\hline Becium grandflorum & Eritrea and Ethiopia & Near threatened \\
\hline Leucas abyssinica & Eritrea and Ethiopia & Least concern \\
\hline Rhus glutinosa & Eritrea and Ethiopia & Least concern \\
\hline
\end{tabular}

\section{Conclusion and Recommendations}

In this study, 115 plant species of medicinal importance were recorded and documented (see appendix).Most of these medicinal plants are harvested from natural stands followed by homegarden. They are also found growing sporadically in natural forests, hills, mountains, churches, home gardens, river and roadsides. They are the predominant sources of traditional medicine for traditional healers. Shrubs were found to be the most dominant growth forms in the preparation of traditional remedies followed by herbs, trees, climbers and trailing herbs.

Like in other parts of Eritrea, people of the sub region Logo-anseba have traditional practices which have been accumulated for generations to treat both human and animals. They use different parts of plants to prepare remedies (roots, leaves, stems, barks, and other plants structures). The traditional medicine practitioners have developed methods of diagnosis and treatment and they also know very well about the preparations, route of administrations and dosage about the traditional medicinal plants.

People in the study area use medicinal plants not only for healthcare but also as financial income, cultural identity and livelihood security but also as food, firewood, charcoal, construction and furniture. However, due to various reasons, many of medicinal plants were reported to be threatened and lost. This demands an urgent attention to conserve such vital resources to optimize their use in the primary healthcare system. It was also reported that the elders, who know more about medicinal plants, might die without sharing their traditional knowledge to the young generation. Therefore, documentation is important in order to transfer the knowledge to the next generation since it can be the base for the invention of modern drugs.

It can be concluded that, the documentation of this traditional knowledge is inevitable to throw light in to the field of herbal research and to improve socio-economic development of the people. Moreover, all efforts should be made to conserve these medicinal plants in a proper way for the health benefits of this community. This work is based on the Indigenous knowledge on medicinal plants and methods of treatment against common ailments prevailing among the people of the sub region Logo-anseba.

\section{Based on the Results and the Conclusions Given the Following Recommendations are Forwarded:}

* Traditional herbalists should be acquainted with and abide by the ethics and fundamental principles of medicines, so that the medicine has a positive impact on the health of the society and it should be given in precise dosage. 
* Medicinal properties of the plant species used should be properly known.

* The IK and skill of traditional medicine practitioners have to be encouraged and protected from the wrong perception that leads to accusation.

* To give more support to the above findings, further scientific investigations are needed for the isolation of active principles and pharmacological evaluation of the different medicinal plant species reported in this study.

* All efforts should be made to conserve these medicinal plants in a scientific way for the health benefit of this community.

* Marketing potential and market trends should be properly understood and implemented, in other words efforts should be made to facilitate conditions where by traditional medicines could be supplied to the market to maintain their traditional values.

* There should be joint responsibilities from the local people, healers and government sectors for the issues of medicinal plants and indigenous knowledge to conserve in their natural habitat and build up their significance.

* Create awareness to encourage the population in order to conserve the threatened and endangered plant species in their natural habitats and home-gardens.

* Medicinal plant management and conservation must be integrated in other sectors such as in health to foster better use of plant materials and in education to build up awareness of the need for protection. Government must provide incentives to farmers for the cultivation of medicinal plants to ensure their conservation issues.

\section{Reference}

[1] Abbink, J. (1995): Medicinal and Ritual Plants of the Ethiopian South West An account of Recent Research. Indigenous Knowledge and Development Monitor, Vol3 (2): pp6-8.

[2] Amare Getahun (1976): Some Common Medicinal and Poisonous Plants Used in Ethiopian Folk Medicine.Ethiop.J. Biol. Sci., Vol3, pp. 63.

[3] Bayafers Tamene (2000): A Floristic Analysis and Ethno botanical Study of the Semi Wet land of Cheffa Area, South Wello, Ethiopia. M. Sc. Thesis, Addis Ababa University.

[4] Cotton, C. M. (1996): Ethnobotany: Principles and Applications. John Wiley and Sons Ltd.Chichister, England, Vol 1: pp 347.

[5] CSOGB (2010): Central Statistical Office of Region Gash Barka Eritrea.

[6] Cunningham, A. B. (1996): People, park and plant use recommendation for multiple uses Zones and Development alternatives around Bwindi. Impenetrable National Park Uganda. In People and Plant Working Paper, Vol 4: pp 18-23. UNESCO, Paris.

[7] Dawit Abebe (2001): The role of medicinal plants in health care coverage of Ethiopia. The possible benefits of integration. In: Conservation and Sustainable Use of Medicinal Plants in Ethiopia, pp. 6-21, (Medhin Zewdu and Abebe Demissie eds). Proceedings of the National Work shopon Biodiversity Conservation and Sustainable Use of Medicinal Plants in Ethiopia, 28 April01 May 1998, IBCR, Addis Ababa.

[8] Dawit Abebe and Ahadu Ayehu (1993): Medicinal Plants and Eenigmatic Health Practices of Northern Ethiopia. Addis Ababa, B.S.P.E. pp. 511

[9] Debela Hunde, Zemede Asfaw and Ensermu Kelbessa (2004).Use and Management of Ethnobotanical Medicinal Plants by Indigenous People in Boosat, Welenchiti area. Ethiop.J. Biol. Sci., Vol3 (2): pp113-132.

[10] Endalew Amenu (2007): Use and management of Medicinal plants by Indigenous People of Ejaji Area (Chelya Wereda) West Shoa, Ethiopia: An Ethnobotanical Approach, M.Sc. Thesis Addis Abeba University.

[11] Ermias Lulekal, Ensermu Kelbessa, Tamrat Bekele and Haile Yineger (2008): An Ethnobotanical study of medicinal plants in Mana Angetu District, southeastern Ethiopia. Journal of Ethnobiology and Ethnomedicine.http://www.ethnobiomed.com/content/4/1/10. Accessed on March 20, 2010.

[12] Esknder Berhane (2001): Ethnobotany: A Book of Medicinal application of plants. Semhar printing press, Asmara, Eritrea. (Tgrigna).

[13] Fichtl, R. and Admasu Adi (1994): Honey bee flora of Ethiopia. Margraf Verlag, Wikersheim, Germany, pp. 510

[14] Fisseha Mesfin, Sebsebe Demissew and Tilahun Teklehaymanot (2009): An Ethnobotanical study of medicinal plants in Wonago Wereda, SNNPR, Ethiopia. Journal of Ethnobiology and EthnomedicineVol5:pp 28.

[15] Iwu, M.M (1993): Handbook of African Traditional Medicinal plants. Boca Raton. Ann Arbor. London. CRC Press, Inc. Pp. 43

[16] Martin, G.J. (1995): Ethnobotany: A method Manual. A ‘People and Plants' Conservation Manual. Champman and Hall, London, pp. 268.

[17] Mirutse Giday and Gobena Ameni (2003): An Ethnobotanical Survey on Plants of Veterinary Importance in Two Weredas of Southern Tigray, Northern Ethiopia.SINET: Ethiop.J. Sci., Vol26(2):pp 123 -136.

[18] Nugusse Amsalu (2010): Ethno botanical study of medicinal plants used in Farta Wereda, Southern Gonder, Amhara sub region Ethiopia. Addis Ababa University a Master's of Science thesis.

[19] Prakash C. Phondani, Arvind Bhatt, Esam Elsarrag, Yousef A. Horr (2015): Ethno botanical magnitude towards sustainable utilization of wild foliage in Arabian Desert. Journal of Traditional and Complementary Medicine 1-10

[20] Russo, L. (2000): Ethiopia - Non-Wood Forest Products and Forest Services. FAO Forestry.

[21] Senai Weldeab (2010). 'Legislative Regulation of Traditional Medicinal Knowledge in Eritrea vis-à vis Eritrea's Commitments under the Convention on Biological Diversity: Issues and Alternatives'6/2 Law, Environment and Development Journal pp. 130.

[22] Shushan Ghirmay (2002): Traditional use of traditional medicinal plants in highland sub region of Eritrea, M.Sc. Thesis, Agricultural University of Norway.

[23] Singhal, R. (2005): Medicinal Plants and Primary Health Care: The Role of Gender. SAGE, 70 London. Journal of Health Management, vol 7(2):pp 277-293.

[24] Tecleab G., Thomas, K., Tesfalem, R., Gebrehiwet, M. and Bereket, T, (2009) Antibacterial activity and phytochemical study of nine medicinal plants from Eritrea, Pharmacologyonline journalVol3: pp546 -555. 
[25] Thomas, K., Tecleab, G., Gebrehiwet, M and Bereket, T, (2007) Chemical Composition and Antibacterial activity of Essential oils from salvia species of Eritrea, Pharmacologyonline journalVol3: pp546-555.

[26] Vivero, T and Sebsebe Demisew, (2005) the red list of endemic trees and shrubs of Ethiopia and Eritrea. Fauna Flora International, Cambridge, UK.

[27] WHO (2003): African Traditional Medicine: Our Culture, Our Future. African Health Monitor, Vol 4: pp 11 a magazine of WHO Sub regional Office for Africa, Nairobi, Kenya.

[28] Zemede Asfaw (2001): The role of home gardens in production and conservation of medicinal plants. In: Conservation and Sustainable Use of Medicinal Plants in Ethiopia. (Medhin Zewdu and Abebe Demissie eds) Proceedings of the National Workshop on Biodiversity conservation and Sustainable Use of Medicinal Plants in Ethiopia, pp. 76-91, IBCR, Addis Ababa, Ethiopia.

Appendix 1: List of Medicinal Plants and their Use.

\begin{tabular}{|c|c|c|c|}
\hline Scientific name & Medicinal use & Scientific name & Medicinal use \\
\hline Acacia etbaica & Anti-biotics anti-helminthic & Clutia abyssinica & Gastritis diabetes \\
\hline Acacia sieberiana & Anti-helminthic & Coffea arabica & Anti-diarrhea anti-biotic \\
\hline Achyranthes aspera & Anti-inflammation & Cometes abyssinica & Sun strike, insecticide \\
\hline Aenva lanata & 'Gonfi', 'Gerefta' evil ayes & Commelina africana & Anti-Hypertension \\
\hline Allium cepa & Anti-diabetes anti-fungal & Commicanpus pedunculasus & Anti-snake anti-scorpionvenor \\
\hline Allium sativum & Anti-hypertension anti-asthma & Cordia africana & Jaundice skin trouble \\
\hline Aloe camperi & Anti-malaria anti-hepatomegaly & Croton macrostychus & Hepatitis scorpionvenom \\
\hline Aloe elegance & Anti-diabetes anti-biotics & Cucumis dipsaceus & Anti-helminthic \\
\hline Argemone mexicana & Anti-biotics & Cucurbita pepo & Endo-parasites \\
\hline Aspilia mosambicensis & To treat kidney problems & Cynoglossum lanceolatum & Ear-infection constipation \\
\hline Astragalus atropiloswlus & Anti-hemorthoids & Datura stramoniwm & Anti fungal tooth ache \\
\hline Azadiviachta indica & Anti-fungal anti-hemorthoids & Daucus carota & Anti-diabetes anti-gastritis \\
\hline Balanites aeguptiaca & Purgative anti-malaria & Dichrostachys cinerea & Impotency \\
\hline Barleria eranthemoides & Eye problems anti-tonsillitis & Dodonaea angustifolia & Anti-biotics anti-helminthic \\
\hline Becium grandiflorwm & Anti-cramps & Eucalvptus camaldulensis & Anti-Rheumatism anti-biotics \\
\hline Bidens pilosa & 'Gonfi' 'Gerefta' & Euclea racemosa & Hepatitis malaria \\
\hline Boscia angustifolia & Snake bites anti- gastritis & Euphorbia abyssinica & Anti-biotic abdominalpain \\
\hline Boscia salicifolia & Scabies & Euphorbia camaldulensis & Jaundice, wound heeling \\
\hline Brassica olearacea & Anti-rheumatism anti-gastritis & Ficus vasta & Insecticides \\
\hline Buddelia polvstachya & Insecticides evil eyes & Foeniculwn vulgare & Cough, reduce obesity \\
\hline Calpumia awea & Anti-snake anti scorpionvenom & Grewia ferrugenia & Hemorrhage endoparasites \\
\hline Capparis tomentosa & Cold cough & Heliotropium cinerascens & Anti-tonsillitis \\
\hline Carica papaya & Anti-amoeba anti-diabetes & Hibiscus eriospenus & Asthma \\
\hline Carissa spinarum & Anti-malaria anti-hepatomegaly & Hibiscus macranthus & Asthma \\
\hline Chenopodium album & Hypertension & Hordeum vulgare & Gastritis, diabetes \\
\hline Cichorium endiva & Anti-diabetes & Indigofera arrecta & Sun strike, 'Gerefta' \\
\hline Cissus rotandofolia & Antibiotic 'Gonfi' & Jasminum gradiflorwn & Eye problem, tape warm \\
\hline Citrus limon & Digestion problem as thma & Justicia cordata & Warts \\
\hline Citrus sinensis & Cough head ache & Justicia schimperiana & 'Gerefta' \\
\hline Clematis simensis & Leishmaniasis & Kalanchoe mamarata & Cold Gonorrhea \\
\hline
\end{tabular}

Appendix: Cont'd

\begin{tabular}{|c|c|c|c|}
\hline Scientific name & Medicinal use & Scientific name & Medicinal use \\
\hline Lannea fructicosa & Sun strike evil eyes & Rumex nervosus & Itching eczema \\
\hline Lepidium sativum & TB hepatitis & Ruta chalepnesis & Cough cold \\
\hline Leucas abyssinica & Endo parasites cold & Sageretia thea & Tonsillitis \\
\hline Linum usitatissimun & Limb inflammation & Schinus molle & Diarrhea, cold cough \\
\hline Lycopersicum esculentum & Inflammation of nails & Senna alexandrina & Hepatitis hepatomegaly \\
\hline Maytenus arbuitofolia & Head ache eye problem & Senna singueana & Vomiting loss of appetite \\
\hline Maytenus senegalensis & Arthritis eye problem & Sida schimperiana & 'Gonfi' \\
\hline Meriandra dianthera & Diabetes hypertension & Solanum nigrum & Anti-snake scorpion venom \\
\hline Nicandra physaloides & Tooth ache Cough & Solanum shcimperianum & Scabies \\
\hline Nicotiana glauca & 'Gerefta' tooth ache & Solanum tuberosum & used to clean the eye \\
\hline Nicotiana tabaccum & Tooth ache & Sorghum bicolor & Limb inflammation fire accident \\
\hline Ocimum basilicum & Vomiting head ache & Syzygium guineens & Cough \\
\hline Ocimum forskolei & Cough malaria & Tagetes minuta & Used as insecticides \\
\hline Olea europeana/ cuspidate & Tooth ache fungal disease & Tamarindus indica & Cold malaria \\
\hline Osyris quadrpartita & Gastritis & Terminallia brownii & Hepatitis used as purgative \\
\hline Otostegia fruticos $\alpha$ & Tonsillitis endo parasites & Trigonellafoenum-graecum & Hypertension diabetes \\
\hline Otostegia integrifolia & Abdominal-pain tonsillitis & Verbascum sinaiticum & 'Gerefta' sun strike \\
\hline Petrolobium stellatusm & Eye ear infection & Vernonia amygdalina & Anti-biotic \\
\hline Phytolacca do decandra & Gastritis & Vitis viniferia & Cold loss of appetite \\
\hline Plumbago zeylanica & Snake venom evil eye & Withania somnifera & Anti-biotics 'Gonfi' \\
\hline Prunus persica & Cold tonsillitis & Xanthium stromarium & Anti- helminthic \\
\hline Psiadia punctulata & Abdominal pain & Ximenia americana & Tonsillitis \\
\hline Psiduim guajava & Dysentery & Zea mays & Kidney problem \\
\hline Rhamnus prinoides & Hepatitis tonsillitis & Zehneria scabra & 'Gerefta' \\
\hline Rhus glutinosa & Ecto parasites & Zingiber officinale & Rheumatism reduce bleeding \\
\hline Ricinus communis & Anti-termites anti- fungal & Ziziphus mucronata & Fungal diseases \\
\hline Rosa abyssinica & Anti-termites & Ziziphus spina-christi & Cough fungal diseases \\
\hline Rosmarinus officinalis & Hypertension diabetes & & \\
\hline
\end{tabular}

